\title{
Hepatite Delta no Estado de Mato Grosso: apresentação de cinoo casos
}

\author{
Hepatitis Delta in the State of Mato Grosso, \\ Brazil: report of five cases
}

\section{Luciano Corrêa Ribeiro e Francisco José Dutra Souto'1}

\begin{abstract}
Resumo Cinco casos graves de infecção pelos vírus das hepatites $B$ e $D$ foram diagnosticados em jovens oriundos do norte do Mato Grosso, onde é comum a ocorrência de hepatite $B$, mas não de hepatite $D$. A proximidade com os Estados do Acre e do Amazonas e a migração interna podem explicar a introdução do vírus da hepatite $D$ na região. Os autores salientam a necessidade de manter vigilância epidemiológica para casos de hepatite $D$ na região.
\end{abstract}

Palavras-chaves: Hepatite B. Hepatite D. Hepatite delta. Amazônia. Mato Grosso. Cirrose.

Abstract Five cases of hepatitis $B$ and $D$ superinfection in teenagers from the northernmost region of Mato Grosso State are reported. Hepatitis $B$ is high prevalent there, but not hepatitis $D$. The proximity to the States of Acre and Amazonas and intense migration may be introducing the virus into the region. Necessity for the surveillance of hepatitis $D$ in northern Mato Grosso is emphasized.

Key-words: Hepatitis B. Hepatitis D (Hepatitis delta). Amazon. Mato Grosso. Cirrhosis.

A co-infecção ou superinfecção pelo vírus da hepatite $D(V H D)$ é uma ocorrência muito temida nas áreas onde a hepatite B é comum. O VHD pode eventualmente desencadear a instalação de hepatite grave, com insuficiência hepática aguda, ou, mais comumente, fazer com que um portador de assintomático do VHB desenvolva hepatite crônica ativa ${ }^{9}$. Esses indivíduos podem evoluir mais rapidamente para cirrose.

A Amazônia é uma das áreas de maior prevalência da hepatite $B$, estando a incidência de superinfecção pelo VHD entre os maiores do mundo $^{3613}$. O VHD foi associado com a etiologia de muitas formas graves de doença ictérica aguda, que acometeram diversas localidades ribeirinhas e indígenas em países da Amazônia Ocidental, incluindo o Brasil ${ }^{24}$. Esse fato pode ser observado na subbacia do Rio Purus, interessando o sudoeste do Estado do Amazonas e o Estado do Acre $(25 \%)^{2}$. Mesmo em localidades amazônicas em que há prevalência baixa a moderada $(1,6 \%)$ de pessoas com HBsAgpositivo, como em Barcelos, a superinfecção pelo VHD está presente com alta freqüência $(38,5 \%)^{1}$.

No norte do Estado do Mato Grosso localizase a parte mais meridional da Amazônia brasileira. Pouco era conhecido sobre a prevalência da hepatite $B$ nessa região até a realização de estudos nos anos 90 , mostrando prevalência moderada a alta do VHB em diversos municípios ${ }^{101112}$. Apesar desses índices preocupantes, a quase inexistência da hepatite $D$ nas populações estudadas pode ser considerada como fator positivo. Provavelmente, esse fato foi o responsável pela baixa mortalidade

\footnotetext{
1. Hospital Universitário Júlio Müller, Departamento de Clínica Médica da Faculdade de Ciências Médicas da Universidade Federal de Mato Grosso.

Endereço para correspondência: Dr. Luciano Corrêa Ribeiro. Núcleo de Estudos de Doenças Infecciosas e Tropicais de Mato Grosso/ Hospital Júlio Müller. Rua L s/nº, Jardim Alvorada, 78048-790 Cuiabá, MT, Brasil.

Telefax: 5565 615-7302.

e-mail: lucorrea@zaz.com.br

Recebido para publicação em 5/1/2000.
} 
verificada nos surtos de hepatite registrados na região até agora ${ }^{710}$.

No entanto, nos últimos anos, casos de doença hepática avançada entre jovens oriundos do norte de Mato Grosso estão sendo identificados regularmente no Hospital da Universidade Federal de Mato Grosso, que funciona como referência para casos de hepatites virais no Estado. Este relato descreve cinco casos registrados entre 1997 e 1999.

\section{RELATO DOS CASOS}

Foram acompanhados, por ordem cronológica, os seguintes casos (resultados dos exames na Tabela 1).

Caso 1. GAA, do sexo feminino, com16 anos de idade, natural de Juara (MT), tendo vivido em Peixoto de Azevedo (MT) e, no momento da internação, residindo em Sinop (MT). Foi internada em 24/3/97 com edema e icterícia desenvolvidos recentemente. Tinha história de malária e hepatite aos 4 anos de idade. Investigação inicial mostrou atividade de protrombina (TAP) de $32 \%$; albumina de $2,5 \mathrm{~g} / \mathrm{dl}$; bilirrubinas totais de $4,0 \mathrm{~g} / \mathrm{dl}$, alanino-glutamiltransferase (ALT) de $136 \mathrm{U} / \mathrm{ml}$; e aspartato-glutamiltransferase de $66 \mathrm{U} / \mathrm{ml}$. A

Tabela 1 - Resultados dos principais exames complementares nos cinco casos relatados.

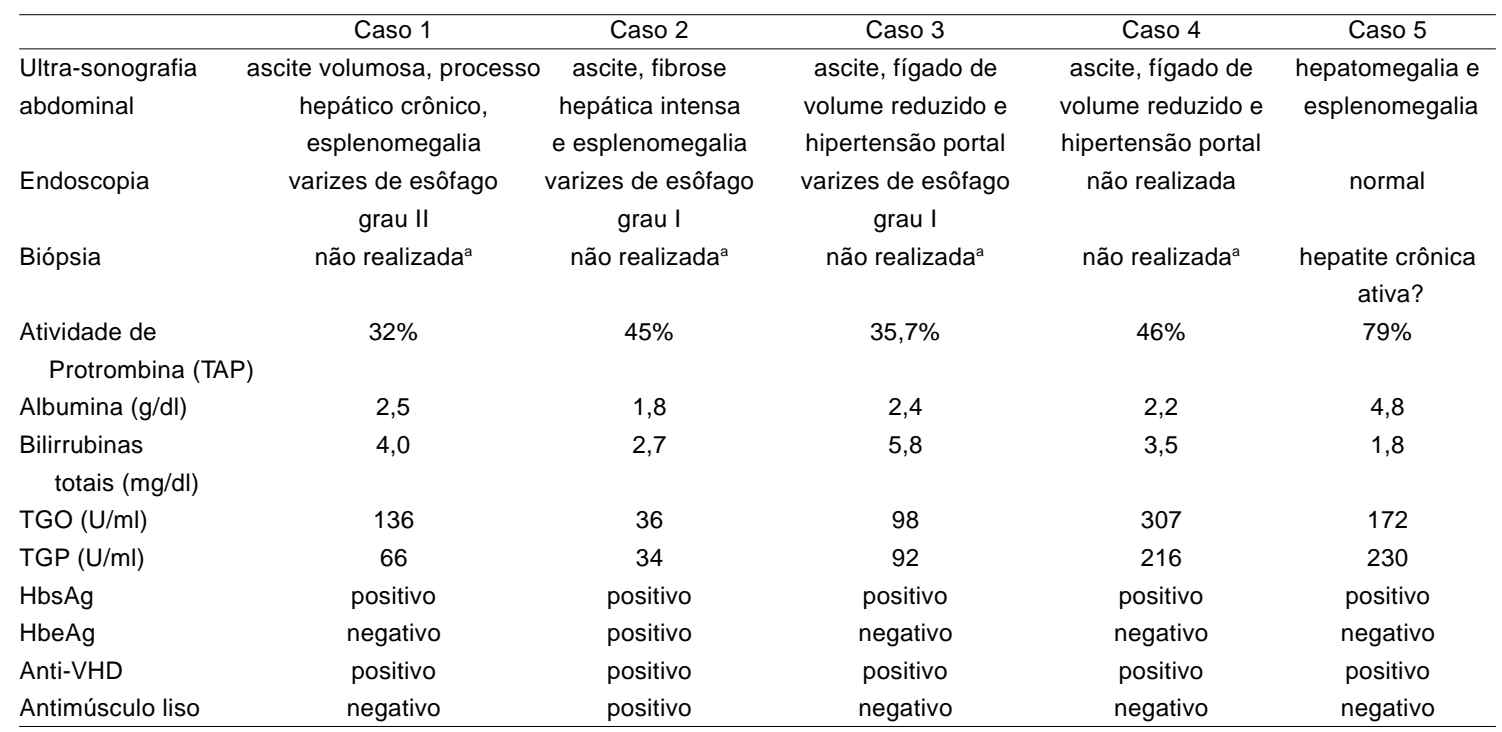

${ }^{a}$ Biopsia não foi realizada por causa do tempo prolongado de protrombina e pela presença de ascite.

ultra-sonografia mostrava ascite volumosa, esplenomegalia e sinais de doença parenquimatosa crônica do fígado. Endoscopia digestiva revelou varizes esofagianas de grau 2. A pesquisa de marcadores sorológicos por enzimoimunoensaio (ELISA), evidenciou a presença de infecção pelos vírus das hepatites B e D. Após 34 dias de internação, recebeu alta. Voltou, porém, a ser internada em 19/06/97, por apresentar anasarca, icterícia, encefalopatia hepática e hemorragia digestiva. Evoluiu para óbito em 30/6/97.

Caso 2. AMS, do sexo feminino, com 17 anos, natural do Acre, residindo em Tangará da Serra
(MT). Foi internada em 10/01/98 com anasarca e esplenomegalia de 2 meses de evolução. Referia episódio de malária no passado. Seus exames mostravam: TAP: $45 \%$; ALT: $37 \mathrm{U} / \mathrm{ml}$; AST: $75 \mathrm{U} / \mathrm{ml}$; albumina: $1,8 \mathrm{~g} / \mathrm{dl}$; bilirubina totais: $1,3 \mathrm{mg} / \mathrm{dl}$. Testes sorológicos por ELISA confirmaram a infecção vírus da hepatite $\mathrm{B}$, com HBeAg-positivo, além de hepatite $\mathrm{D}$. Anticorpo antimúsculo liso foi fortemente positivo. Ultra-sonografia mostrou ascite, hipertensão portal e sinais de cirrose. Após melhora clínica recebeu alta para acompanhamento ambulatorial, a que se submeteu até 05/98, quando não mais procurou o serviço. 
Caso 3. CS, do sexo masculino, com 19 anos de idade, paranaense, oriundo de Juruena (MT). Foi inicialmente atendido, em 10/9/98, com ascite volumosa, edema de membros inferiores e icterícia. Seus exames mostraram ALT: $92 \mathrm{U} / \mathrm{ml}$; AST: $98 \mathrm{U} / \mathrm{ml}$; albumina: $2,4 \mathrm{mg} / \mathrm{dl}$; bilirrubina total: $5,8 \mathrm{mg} / \mathrm{dl}$. Ultra-sonografia evidenciou ascite ,com redução do volume hepático e hipertensão portal. Os testes sorológicos (ELISA) foram positivos para hepatites $B$ e Delta. Foi internado e tratado com diuréticos. Recebeu alta após 6 dias, com melhora do edema. Devido às evidências de cirrose avançada, optou-se por não realizar tratamento com interferon. Após 1 ano de acompanhamento ambulatorial sem intercorrências, voltou a apresentar intensificação do edema e da icterícia, em vigência de tratamento e dieta adequados. Mudou-se recentemente para Curitiba, estando na lista de espera para transplante hepático.

Caso 4. GD, com 14 anos de idade, sexo masculino, catarinense, tendo residido a maior parte de sua vida em Cotriguaçu (MT). Morava há 4 anos em Lucas do Rio Verde (MT). Deu entrada em nosso ambulatório em outubro de 1998, com icterícia, ginecomastia e edema de membros inferiores. Quadro clínico que aparecera nos meses anteriores. Avaliação laboratorial mostrou TAP: $46 \%$; albumina: 2,2g/dl; AST: $307 \mathrm{U} / \mathrm{ml}$; ALT: $216 \mathrm{U} / \mathrm{ml}$; bilirrubina totais: $3,5 \mathrm{mg} / \mathrm{dl}$. Ultra- sonografia do abdome revelou fígado com volume reduzido, ascite e hipertensão portal. Os exames sorológicos (ELISA), mostraram presença de hepatites B e D. Responsáveis pela criança, informados sobre o mau prognóstico do caso, concordaram em procurar serviço de transplante hepático. O paciente foi incluído em lista de espera para transplante hepático em serviço de Porto Alegre (RS), onde passou a morar desde fevereiro de 1999. Foi realizado transplante hepático em setembro de 1999, encontrando-se o paciente em bom estado geral sob acompanhamento naquela cidade.

Caso 5. LAR, do sexo masculino, de 13 anos de idade, oriundo de Cotriguaçu (MT), começou a apresentar icterícia 6 meses antes da internação em nosso Hospital, que se deu em 14/7/99. Na admissão, apresentava-se ictérico e com esplenomegalia. Exames mostravam TAP: 79\%; albumina: 4,8g/dl; AST: $172 \mathrm{U} / \mathrm{ml}$; ALT: $230 \mathrm{U} / \mathrm{ml}$; bilirrubina: $1,8 \mathrm{mg} / \mathrm{dl}$. A endoscopia digestiva alta foi normal e a ultra-sonografia mostrava hepatoesplenomegalia. A pesquisa de marcadores sorológicos por ELISA, evidenciou a presença das hepatite $B$ e $D$. A biópsia hepática revelou hepatite crônica ativa, com formação de pontes centro-porta e necrose em saca-bocado. No momento, o paciente está em uso de interferonalfa.

\section{DISCUSSÃO}

Os casos apresentados ressaltam a dramaticidade da superinfecção VHB-VHD, que pode levar à cirrose em espaço de tempo muito mais curto que o usualmente observado com a infecção crônica isolada pelo VHB. Como a hepatite $B$ é endêmica na região amazônica e freqüentemente acomete indivíduos ainda na infância, as conseqüências desastrosas dessa associação podem ser notadas já na segunda década de vida, como ilustram os 5 casos aqui relatados.

Pode-se indagar se o segundo caso se tratava exclusivamente de superinfecção B e D ou se havia também associação de hepatite autoimune, uma vez que elevados títulos de autoanticorpos contra músculo liso (principal marcador dessa doença) estavam presentes. Sabe-se, porém, que a hepatite crônica viral pode desencadear fenômenos auto-imunes e o aparecimento destes auto-anticorpos no sangue ${ }^{5}$. Além disso, a presença no soro de $\mathrm{HBeAg}$ sugeria replicação ativa do VHB. De modo que, mesmo sem poder afastar completamente a ocorrência concomitante de hepatite auto-imune, podemos considerar a presença de hepatite crônica viral como certa.

No caso 5, a descoberta do problema deu-se em estágio da doença mais precoce do que nos outros, fundamentando a tentativa de eliminar a dupla infecção viral com uso de intérferon. Sabemos, no entanto, que as doses de intérferon utilizadas no tratamento da hepatite $D$ são elevadas e os resultados não têm sido promissores ${ }^{9}$.

A maioria dos casos era oriunda ou já vivera no noroeste do Mato Grosso, região onde foram detectados surtos comunitários de hepatite $B$ na década de 90, em área de intensa migração. Essa região faz fronteira com os Estados do Amazonas e Rondônia, não sendo distante do Acre, onde tem sido registrado alta freqüência de hepatite $D$ nas últimas décadas. Apenas um dos nossos doentes não passou pelo noroeste mato-grossense, mas nasceu no Acre. 
Com a intensificação da ocupação humana no norte matogrossense, a abertura de novas estradas, o desmatamento e o aumento da atividade econômica na região, prevê-se maior intercâmbio entre os Estados amazônicos. Esse fato poderá proporcionar transmissão mais intensa do VHD, a partir de pessoas procedentes do Acre, de Rondônia e do Amazonas, para a população do norte de Mato Grosso, com preocupantes conseqüências para aqueles que são portadores crônicos asssintomáticos do VHB.

O modo de prevenção atualmente disponível contra a infecção pelo VHD é a vacinação contra o VHB, que vem sendo efetuada continuamente na Amazônia há cerca de uma década. A inclusão dessa vacina no calendário do Programa
Nacional de Imunizações e a regularização de seu fornecimento a partir de 1998, constituem grande avanço na luta contra a hepatite B e, indiretamente, também, contra a hepatite $D$. No entanto, grande contigente de portadores do VHB no norte do país não pode beneficiar-se da vacina e são potenciais vítimas da infecção pelo VHD. Como o desenvolvimento de uma vacina contra o VHD, que possa proteger esses portadores, ainda está longe de ser alcançada, a única maneira de evitar o contágio desses indivíduos é evitar sua exposição ao agente ${ }^{9}$. É, portanto, recomendável que se exerça vigilância epidemiológica no norte do Mato Grosso, objetivando detectar possível aumento da prevalência do anti-VHD entre os indivíduos identificados como portadores do VHB.

\section{REFERÊNCIAS BIBLIOGRÁFICAS}

1. Arboleda M, Castilho MC, Fonseca JC, Albuquerque BC, Saboia RC, Yoshida CF. Epidemiological aspects of hepatitis $B$ and $D$ virus infection in the northern region of Amazonas, Brazil. Transactions of Royal Society of Tropical Medicine and Hygiene 89:481-483, 1995.

2. Bensabath G, Hadler SC, Soares MC, Fields H, Dias LB, Popper H, Maynard JE. Hepatitis delta virus infection and Labrea hepatitis. Prevalence and role in fulminant hepatitis in the Amazon basin. Journal of American Medical Association 258:479-483, 1987.

3. Bensabath G, Soares MC. A hepatite B e delta em Boca do Acre, Alto Purus. Moderna Hepatologia 14:36-40, 1989.

4. Casey JL, Niro GA, Engle RE, Veja A, Gomez H, McCarthy M, Watts DM, Hyams KC, Gerin JL. Hepatitis $B$ virus/hepatitis $D$ virus coinfection in outbreak of acute hepatitis in the Peruvian Amazon basin: the roles of HDV genotype III and HBV genotype F. Journal of Infectious Diseases 174:920-926, 1996.

5. Chan HL, Lok AS. Hepatitis B in adults. Clinics in Liver Diseases 3:291-307, 1999.

6. Fonseca JC, Simonetti SR, Schatzmayr HG, Castejón MJ, Cesário AL, Simonetti P. Prevalence of infection with hepatitis delta virus among carriers of hepatitis B surface antigen in Amazonas State, Brazil. Transactions of Royal Society of Tropical Medicine and Hygiene 82:469-471, 1988.
7. Fundação Nacional de Saúde, Ministério da Saúde. Relatório técnico sobre surto de doença ictérica na Gleba Colniza, município de Aripuanã, Mato Grosso, 1992.

8. Hadler SC, Monzon M, Ponzetto A, Anzola E, Rivero D, Mondolfi A, Bracho A, Francis DP, Gerber MA, Thung S, Gerin J, Maynard JE, Popper H, Purcell RH. Delta virus infection and severe hepatitis. An epidemic in the Yucpa Indians of Venezuela Annals of Internal Medicine 100:339344, 1984.

9. Hadziyannis SJ. Hepatitis D. Clinics in Liver Disease. 3:309-325, 1999.

10. Souto FJ, Fontes CJ, Gaspar AM. Outbreak of hepatitis $B$ virus in recent arrivals to the Brazilian Amazon. Journal of Medical Virology 56:4-9, 1998.

11. Souto FJ, Fontes CJ, Gaspar AM, Lyra LG. Hepatitis B virus infection in immigrants to the southern Brazilian Amazon. Transactions of Royal Society of Tropical Medicine and Hygiene 92:282-284, 1998.

12. Souto FJ, Fontes CJ, Gaspar AM, Paraná R, Lyra LG. Concomitant high prevalence of hepatitis $C$ virus antibodies and hepatitis B virus markers in a small village of the Amazon region. Revista do Instituto de Medicina Tropical de São Paulo 38:221-223, 1996.

13. Torres JR. Hepatitis B and hepatitis delta virus infection in South America. Gut 38:S48-55, 1996. 